\title{
BMJ Open Preferences for centralised emergency medical services: discrete choice experiment
}

\author{
Nawaraj Bhattarai, ${ }^{1}$ Peter Mcmeekin, ${ }^{2}$ Christopher I Price,${ }^{3}$ Luke Vale ${ }^{1}$
}

To cite: Bhattarai $\mathrm{N}$, Mcmeekin $\mathrm{P}$, Price $\mathrm{Cl}$, et al. Preferences for centralised emergency medical services: discrete choice experiment. BMJ Open 2019;9:e030966. doi:10.1136/ bmjopen-2019-030966

- Prepublication history and additional material for this paper are available online. To view these files, please visit the journal online (http://dx.doi. org/10.1136/bmjopen-2019030966).

Received 10 April 2019 Revised 09 0ctober 2019 Accepted 21 October 2019

D) Check for updates

(c) Author(s) (or their employer(s)) 2019. Re-use permitted under CC BY-NC. No commercial re-use. See rights and permissions. Published by BMJ.

${ }^{1}$ Institute of Health and Society, Newcastle University, Newcastle upon Tyne, UK

${ }^{2}$ Faculty of Health and Life Sciences, University of Northumbria at Newcastle, Newcastle upon Tyne, UK ${ }^{3}$ Institute of Neuroscience, Newcastle University, Newcastle upon Tyne, UK

\section{Correspondence to} Dr Nawaraj Bhattarai; nawaraj.bhattarai@newcastle. ac.uk

\begin{abstract}
Objectives It is desirable that public preferences are established and incorporated in emergency healthcare reforms. The aim of this study was to investigate preferences for local versus centralised provision of all emergency medical services (EMS) and explore what individuals think are important considerations for EMS delivery.
\end{abstract}

Design A discrete choice experiment was conducted. The attributes used in the choice scenarios were: travel time to the hospital, waiting time to be seen, length of stay in the hospital, risks of dying, readmission and opportunity for outpatient care after emergency treatment at a local hospital.

Setting North East England.

Participants Participants were a randomly sampled general population, aged 16 years or above recruited from Healthwatch Northumberland network database of lay members and from clinical contact with Northumbria Healthcare National Health Service Foundation Trust via Patient Experience Team.

Primary and secondary outcome measures Analysis used logistic regression modelling techniques to determine the preference of each attribute. Marginal rates of substitution between attributes were estimated to understand the trade-offs individuals were willing to make. Results Responses were obtained from 148 people (62 completed a web and 86 a postal version). Respondents preferred shorter travel time to hospital, shorter waiting time, fewer number of days in hospital, low risk of death low risk of readmission and outpatient follow-up care in their local hospital. However, individuals were willing to trade off increased travel time and waiting time for highquality centralised care. Individuals were willing to travel 9 min more for a 1-day reduction in length of stay in the hospital, $38 \mathrm{~min}$ for a $1 \%$ reduction in risk of death and 112 min for having outpatient follow-up care at their local hospital.

Conclusions People value centralised EMS if it provides higher quality care and are willing to travel further and wait longer.

\section{BACKGROUND}

The National Health Services (NHS) in the UK faces growing service demands and costs which threaten its sustainability and financial stability. ${ }^{1}$ A radical and transformative change is essential for the NHS to maintain safety and

\section{Strengths and limitations of this study}

The findings of this study might inform decisionmakers redesigning emergency medical services about preferences of potential users of that service.

- Participants were randomly sampled from specific population groups registered with Healthwatch or Northumbria Healthcare National Health Service (NHS) Foundation Trust, and therefore may not represent the general population.

- The attributes used in the discrete choice experiment and their levels were framed to closely represent emergency care in NHS England; however, some other important attributes may have been left out.

quality, but this may reduce immediate access to care for some patients. Increased funding could be a part of the solution but the NHS budget is limited. While all areas of healthcare face challenges and major changes in service provision, those faced by acute hospitals are significant because outcomes can depend on time-critical treatments, demand is rising annually and they are supported by a major proportion of the healthcare budget. ${ }^{2}$

In the UK, consolidation of specialised medical care is one of the service models envisaged by the NHS 'five year forward view'. ${ }^{3}$ It is recommended that emergency care be reconfigured into larger specialised emergency units providing earlier multidisciplinary expertise and associated facilities. ${ }^{4}$ While there exists some condition specific evidence that centralisation of specialist services yields better clinical outcomes and savings, ${ }^{5-7}$ there are arguments against centralisation in terms of poorer access, increased travel time and costs, as well as preferences expressed by patients and the public around the provision of local services. ${ }^{8-12}$

Understanding public preferences about the location and nature of healthcare providers has become an important influence on policy and many European countries have incorporated this information 
into decisions about the organisation of their healthcare systems. ${ }^{13}$ Incorporating patient views in healthcare policy decisions may improve the uptake and efficiency of services. Including patient/public views may also lead to better quality research on treatments and service provision. However, little is known about preferences for the centralisation of emergency medical services (EMS).

The aim of this study was to examine public preferences for the different attributes of centralised EMS in England, reported using tradeoffs between attributes which reflect the key consequences.

\section{METHODS}

A discrete choice experiment (DCE) was used to explore preferences. DCEs provide rich data sources for economic evaluation and decision-making and offer several other advantages compared with other stated preference elicitation methods. ${ }^{1415}$ DCEs involve presenting individuals with a series of hypothetical choices which differ in attributes (characteristics) and their magnitude or levels, and ask them to choose the alternative they prefer in each set. The choices that individuals make from a DCE survey enable researchers to understand the value that individuals place on various levels of healthcare provision attributes. A DCE also allows quantification of the relative importance of attributes in terms of willingness to pay and marginal rates of substitution (MRS) ${ }^{16}$

\section{Attributes and level}

The attributes associated with centralisation were identified from literature ${ }^{17-21}$ and also reflected the key performance measures commonly used in EMS $^{22}$ and key quality indicators in NHS England (table 1). ${ }^{102324} \mathrm{~A}$ long list of attributes and their levels was identified from the literature, but the list was shortened based on their relative importance in our study and for the NHS. After discussions within the research team which also consisted of an experienced senior clinician working in emergency medicine, the identified attributes were assigned discrete levels that were likely to be applicable within the UK NHS and closely reflected the reality. ${ }^{25}$ The design was kept as simple as possible so that respondents can make a tradeoff easily.

\section{Questionnaire design}

A full factorial design incorporating all possible combinations of attributes and levels would have resulted in 2048 (ie, $4^{5} \times 2^{1}$ ) possible scenarios. Therefore, an efficient design, which maximises the statistical efficiency of designs by minimising the predicted standard errors of the parameter estimates (usually the D-error statistic), was used. ${ }^{26}$ An efficient fractional factorial design ${ }^{26} 27$ still generated 20 choice sets. To minimise the potential cognitive burden to the respondents, the choice sets were blocked into 2, with each block having 10 choice sets (see figure 1 for a choice set example). The generation of efficient design requires a priori knowledge of attributes used in the choice model. ${ }^{28}$ The prior ${ }^{28}$ estimates of attribute coefficients used in the final efficient design were derived from a pilot survey (see below). A further three choice sets were added to each block as tests of transitivity $^{2930}$ and monotonicity ${ }^{29}$ - which are tests of theoretical validity and rationality of choice sets used in the DCE. Theoretical validity and rationality checks assessed whether the parameters moved in the expected direction. For example, it was expected that shorter travel time to a hospital is preferred over longer travel time duration. Further details on transitivity and monotonicity tests used are in the online supplementary file.

Table 1 Attributes and levels used in the discrete choice experiment

\begin{tabular}{ll}
\hline Attributes & Levels \\
\hline Travel time to hospital & $<30$ min, 1 hour, 1 and half hours, 2 hours or more \\
$\begin{array}{l}\text { Waiting time in the A\&E department to be seen by a } \\
\text { doctor or nurse who can provide treatment }\end{array}$ & 30 min, 1 hour, 2 and half hours, 4 hours or more \\
Length of stay at the hospital before going home & $\begin{array}{l}1 \text { day or less, } 3 \text { days, } 5 \text { days, } \\
6 \text { days or more }\end{array}$ \\
Risk of dying from the illness & Low (less than 1 in 100 patients), \\
& $\begin{array}{l}\text { Mild (3 in } 100 \text { patients), } \\
\text { Moderate (5 in } 100 \text { patients), }\end{array}$ \\
Risk of being readmitted to the hospital after going & High (more than 7 in 100 patients) \\
home & $\begin{array}{l}\text { Mild (3 in } 100 \text { patients), } \\
\text { Moderate (5 in } 100 \text { patients), } \\
\text { High (more than } 7 \text { in } 100 \text { patients) }\end{array}$ \\
\hline & $\begin{array}{l}\text { At your local hospital, } \\
\text { At a hospital which is about an extra } 1 \text { hour travel time from your local } \\
\text { hospital }\end{array}$ \\
\hline
\end{tabular}

A\&E: Accident and Emergency 


\begin{tabular}{|c|c|c|}
\hline Characteristics & Hospital A & Hospital B \\
\hline Travel time to hospital & 1 and half hours & 1 hour \\
\hline $\begin{array}{l}\text { Waiting time in the A\&E department to be } \\
\text { seen by a doctor or nurse who can } \\
\text { provide treatment }\end{array}$ & 4 hours or more & $\begin{array}{l}\text { Less than } 30 \\
\text { minutes }\end{array}$ \\
\hline $\begin{array}{l}\text { Length of stay at the hospital before } \\
\text { going home }\end{array}$ & 3 days & 5 days \\
\hline $\begin{array}{l}\text { Risk of dying from the illness (..patients } \\
\text { die) }\end{array}$ & $\begin{array}{l}\text { Moderate } \\
\text { ( } 5 \text { in } 100 \text { patients) }\end{array}$ & $\begin{array}{l}\text { Mild } \\
\text { (3 in } 100 \text { patients) }\end{array}$ \\
\hline $\begin{array}{l}\text { Risk of being re-admitted to the hospital } \\
\text { after going home }\end{array}$ & $\begin{array}{l}\text { Mild } \\
\text { ( } 3 \text { in } 100 \text { patients) }\end{array}$ & $\begin{array}{l}\text { Moderate } \\
\text { (5 in } 100 \text { patients) }\end{array}$ \\
\hline $\begin{array}{l}\text { Outpatient care after emergency } \\
\text { treatment }\end{array}$ & $\begin{array}{l}\text { At a hospital which } \\
\text { about an extra } 1 \text { hour } \\
\text { travel time from local } \\
\text { hospital }\end{array}$ & Local hospital \\
\hline $\begin{array}{l}\text { Which hospital would you chose to go in } \\
\text { emergency? (Please tick only one box at } \\
\text { the right) }\end{array}$ & $\square$ & $\square$ \\
\hline
\end{tabular}

Figure 1 Example of choice sets used in the discrete choice experiment.

Altogether, the final design included 13 choice sets in each of the two blocks of DCE choice sets, which were randomly allocated to participants. Choice sets were defined as efficient design using Ngene software V.1.1.1. ${ }^{31}$

The questionnaire also included questions on sociodemographic information such as gender, age group and generic health information. Also included was a question asking the respondents how difficult the DCE task was for them. The respondents were asked to make a forced choice between two alternative hospitals; an opt-out alternative of 'no treatment' in a healthcare emergency lacked realism. The questionnaire used in the survey are in the online supplementary file.

\section{Pretesting and piloting}

The understanding of the attributes and levels was pretested in house among members of the Institute of Health and Society, Newcastle University and piloted on a small non-random sample of potential participants $(n=26)$. Following the pretest and pilot, the wording and display of the survey introduction and the choice sets were revised and simplified. The attribute coefficients generated from the pilot were used as priors to generate the final questionnaire design as described earlier. The priors generated from the pilot are presented in the online supplementary file table S1.

\section{Sample}

The survey sample was recruited from the general public over 16 years of age either registered with Healthwatch Northumberland network database of lay members or with clinical contact with Northumbria Healthcare NHS Foundation Trust and accessed via the Patient Experience Team. Participants were approached between JanuaryApril 2016. The sample represented a general population whose EMS had recently been centralised. Grounded on the recommendations to centralise EMS, ${ }^{34}$ a new specialised emergency care hospital was built at Cramlington in Northumberland, the first of its kind in the UK, with the aim to provide improved quality of care by providing faster access to consultants and diagnostics. ${ }^{10}$ Before June 2015, the EMS were provided from the A\&E departments at three general hospitals within the area: North Tyneside, Wansbeck and Hexham. All of these hospitals are 
operated by Northumbria Healthcare NHS Foundation Trust and they accounted for $90 \%$ of all A\&E visits by the population of Northumberland. ${ }^{10}$ The emergency care provided by the three general hospitals was centralised into the new specialised hospital.

Sample size estimation methods in healthcare DCE studies are currently developing. ${ }^{32}$ Therefore, the sample required for this study was estimated following the rule of thumb suggested by Johnson and Orme ${ }^{32-34}$ using the equation $\mathrm{n}>500 L / T A$ where $L$ is the largest number of levels for any of the choice attributes, $T$ is the number of choice sets and $A$ is the number of alternatives assessed. The required minimum sample was estimated as 100 respondents. However, much larger sample was targeted to allow for heterogeneity between respondents.

Data were collected using postal questionnaires and online. Potential respondents with an email address registered were sent an electronic link to the survey hosted by an online commercial platform, Qualtrics (www.qualtrics.com). Whereas those without email access were sent a paper-copy of the survey. Participants previously identified with visual impairments were sent a paper format of the questionnaire in large font size. The invitation to complete the survey questionnaire explained a description of each of the characteristics used, and how the responses would be used. A clear statement of voluntary participation was included.

\section{Data analysis}

The survey data analysis was based on the random utility framework-the underlying theory that underpins the DCEs. ${ }^{35}$ It has been argued that failure of a validity test would not necessarily mean the respondent was irrational and deletion of responses that fail the validity tests may result in removal of valid preferences which may lead to biassed results. ${ }^{29}$ Moreover, random utility theory is expected to be robust to such violations in validity tests. ${ }^{29}$ Furthermore, qualitative research in this area ${ }^{36} 37$ also revealed that respondents failing the validity tests had rational reasons for doing so. Therefore, all respondents regardless of failing the validity tests were included in the final analysis.

A range of logistic regression modelling approaches were used. Multinomial logit (MNL) (also known as conditional logit analyses), mixed multinomial logit (MIXL) and generalised multinomial logit (GMNL) models were fitted to estimate changes in the preference or utility of each attribute. ${ }^{38}$ MNL assumed homogenous choice across the respondent sample and also assessed the significance of attribute interactions with respondent characteristics. However, the MNL models are based on assumptions of independence of irrelevant alternatives (IIA), independence and identical distribution of error terms (IID) across observations and no heterogeneity across respondents. This may be restrictive and limited in describing human choice behaviour. ${ }^{38}$ Therefore, the MIXL model, ${ }^{3940}$ a popular extension of the MNL model, was also used, which while keeping the IID and not making the IIA assumptions eliminates the limitations of MNL and allowed for choice heterogeneity across respondents. It has been argued that GMNL model allows for the scale heterogeneity by accounting for some respondents who exhibit more random (ie, relatively insensitive to attributes) and extreme choices (ie, near lexicographic-always choosing a particular attribute regardless of others), and thus offers a better fit, outperforming the MIXL model. ${ }^{41}$ Therefore, GMNL model was also used in the analysis. A constant term was not included. Akaike information criterion (AIC) and Bayesian information criterion (BIC) were used as measures of the model fit. The lower the AIC and BIC measures, the more preferred the model. ${ }^{42}$

MRS were calculated, across all models (to account for the models limitations described earlier), to compare respondent preferences on a common value scale and understand the tradeoffs made between two attributes. MRS values were computed using travel time to hospital and time waiting to be seen to present the preferences, so that the tradeoffs could be compared in terms of willingness to travel and willingness to wait. All analyses were undertaken using R statistical programme V.3.2.4. ${ }^{43}$

\section{Patient and public involvement (PPI)}

No patient or public were involved in the design, conduct and reporting of this research. Nevertheless, the priors generated from a pilot study conducted in a sample of general population informed the design of the DCE survey.

Specific written consent was not obtained from participants, but they were made aware that the participation in the survey was voluntary and returning a completed questionnaire was an indication of consent. No personal identifiable information was collected and all data from participants were anonymous. The survey data and other related materials were handled in accordance with the Newcastle University's rules and regulations in place with strict adherence to The Data Protection Act 1998, the law in force at the time of the survey, and the Newcastle University Information Security Guidelines (http://www.ncl.ac.uk/ data.protection/policy.htm).

\section{RESULTS}

In total, 148 respondents completed the survey: 62 online and 86 on paper. While the response rate in the survey sent by post was $13 \%$, it was not possible to assess the response rates in the web version of the survey as we could not verify how many had received the link. However, the weblink was opened on 101 occasions and the response rates in terms of those opening the web version was about $61 \%$. Among the respondents, $44 \%$ reported (answered the survey question on difficulty in completing the DCE) some form of difficulty in completing the choice sets.

\section{Respondent characteristics}

Among the 148 respondents, there were almost twice the number of women compared with men (table 2). Most 


\begin{tabular}{|c|c|}
\hline Characteristics & All \\
\hline Sample (n) & 148 \\
\hline \multicolumn{2}{|l|}{ Age groups } \\
\hline $16-29$ & $4(2.7 \%)$ \\
\hline $30-34$ & $6(4.0 \%)$ \\
\hline $35-39$ & $5(3.4 \%)$ \\
\hline $40-44$ & $4(2.7 \%)$ \\
\hline $45-49$ & $9(6.1 \%)$ \\
\hline $50-54$ & $12(8.1 \%)$ \\
\hline $55-59$ & $19(12.8 \%)$ \\
\hline $60-64$ & $21(14.2 \%)$ \\
\hline $65-69$ & $27(18.0 \%)$ \\
\hline $70-74$ & $17(11.5 \%)$ \\
\hline $75-79$ & $9(6.1 \%)$ \\
\hline $80-84$ & $9(6.1 \%)$ \\
\hline $85+$ & $6(4.0 \%)$ \\
\hline \multicolumn{2}{|l|}{ Gender } \\
\hline Male & $49(33.1 \%)$ \\
\hline Female & $98(66.2 \%)$ \\
\hline Prefer not to reveal & $1(0.7 \%)$ \\
\hline \multicolumn{2}{|l|}{ Health-related quality of life } \\
\hline Mean EQ-VAS score (SD) & $75.50(20.5)$ \\
\hline Mean EQ-5D-5L score (SD) & $0.77(0.2)$ \\
\hline \multicolumn{2}{|l|}{ Emergency experience } \\
\hline Yes & $78(52.7 \%)$ \\
\hline No & $70(47.3 \%)$ \\
\hline
\end{tabular}

respondents aged more than 55 years of age. About half of the respondents had some form of emergency experience in the immediate 12 months before the survey. The health-related quality of life (EuroQol- Visual Analogue Scale $(\mathrm{EQ}-\mathrm{VAS})=75.5$, EuroQol 5 dimensions each with 5 response levels $(E Q-5 D-5 \mathrm{~L})=0.77)$ is similar to that estimated for the UK general population above 55 years of age (which is $\mathrm{EQ}-\mathrm{VAS}=77.6$; $\mathrm{EQ}-5 \mathrm{D}=0.77$ ) ${ }^{44}$

\section{Regression analysis of the DCE data}

Two respondents failed the validity tests. However, an initial regression analysis indicated that the coefficient estimates remained similar regardless of whether those respondents failing the validity tests were included or excluded in the analysis. Therefore, the results on these studies are based on analysis of data from all respondents regardless of failing the validity tests.

Table 3 presents the regression analysis when all the attributes are taken to be continuous. In the 'travel time' and 'waiting time' attributes where the levels had 'less than' or 'more than' categories, only the number of minutes were used, for example, 30 min for 'less than 30 min'. The outpatient follow-up was coded as ' 0 ' for local hospital and ' 1 ' for a distant hospital. The negative and positive signs in the coefficients indicate preference of a lower level and higher level of an attribute, respectively. The coefficient estimates were in line with expectations that individuals would prefer shorter travel time to the hospital, shorter waiting time to receive the service, fewer number of days of length of stay in the hospital, low risk of death, low risk of readmission and outpatient follow-up care after the emergency treatment in their local hospital.

Table 3 also assessed the significance of attribute interactions with respondent characteristics. None of the attribute interactions with respondent age and selfreported health measures were significant which ruled out important differences in preferences of emergency healthcare because of age and health status. Only interactions (travel time*gender, waiting time * gender, waiting time* survey mode, risk of death* gender, risk of death* survey mode, risk of readmission*gender) were significant and these were considered in the final specification (table 3). Results suggest that men have stronger preferences for shorter travel time $(-0.0049$, $\mathrm{p}<0.01)$, shorter waiting time $(-0.0021, \mathrm{p}<0.05)$, lower risk of death $(-0.1047, \mathrm{p}<0.01)$ and lower risk of readmission $(-0.00775, \mathrm{p}<0.01)$ compared with women. Respondents completing the web-based survey showed stronger preferences for less waiting time $(0.0027, \mathrm{p}<0.001)$ and lower risk of death $(0.0862, \mathrm{p}<0.01)$ compared with those completing the survey in paper. In the MIXL model, the significance of attributes remained the same as in MNL model; however, lower AIC and BIC in the MIXL indicated that it provided a better model fit compared with the MNL model. Furthermore, the MIXL model identified heterogeneity among respondents (shown by the statistically significant $\mathrm{SD}$ ). This suggested that MIXL was more appropriate that the MNL model. In the GMNL model, the coefficient estimates retained the signs and significance similar to MNL and MIXL.

Online supplementary table S2 reported the analysis when risk of readmission, risk of death and outpatient follow-up were treated as categorical variables as opposed to continuous variables as they were in table 3 . Categorical data were expressed as dummy variables. There was no evidence of any difference in preferences for the different levels of 'length of stay' in the MNL model. Furthermore, in all three of the statistical models (MNL, MIXL, GMNL), there was no evidence that preferences for the mild of 'risk of death' were any different to the reference category (low risk of death (1 in 100)) across all three models. The magnitude of the coefficients increased in line with the increase in the levels of 'risk of readmission' and 'outpatient follow-up'; however, coefficients for increasing levels of 'risk of readmission' did not increase in a linear manner and there was no evidence that the mild 'risk of readmission' was preferred to low risk of readmission.

\section{Marginal rates of substitution}

The coefficients generated from each of the different regression models in table 3 were used to calculate the 


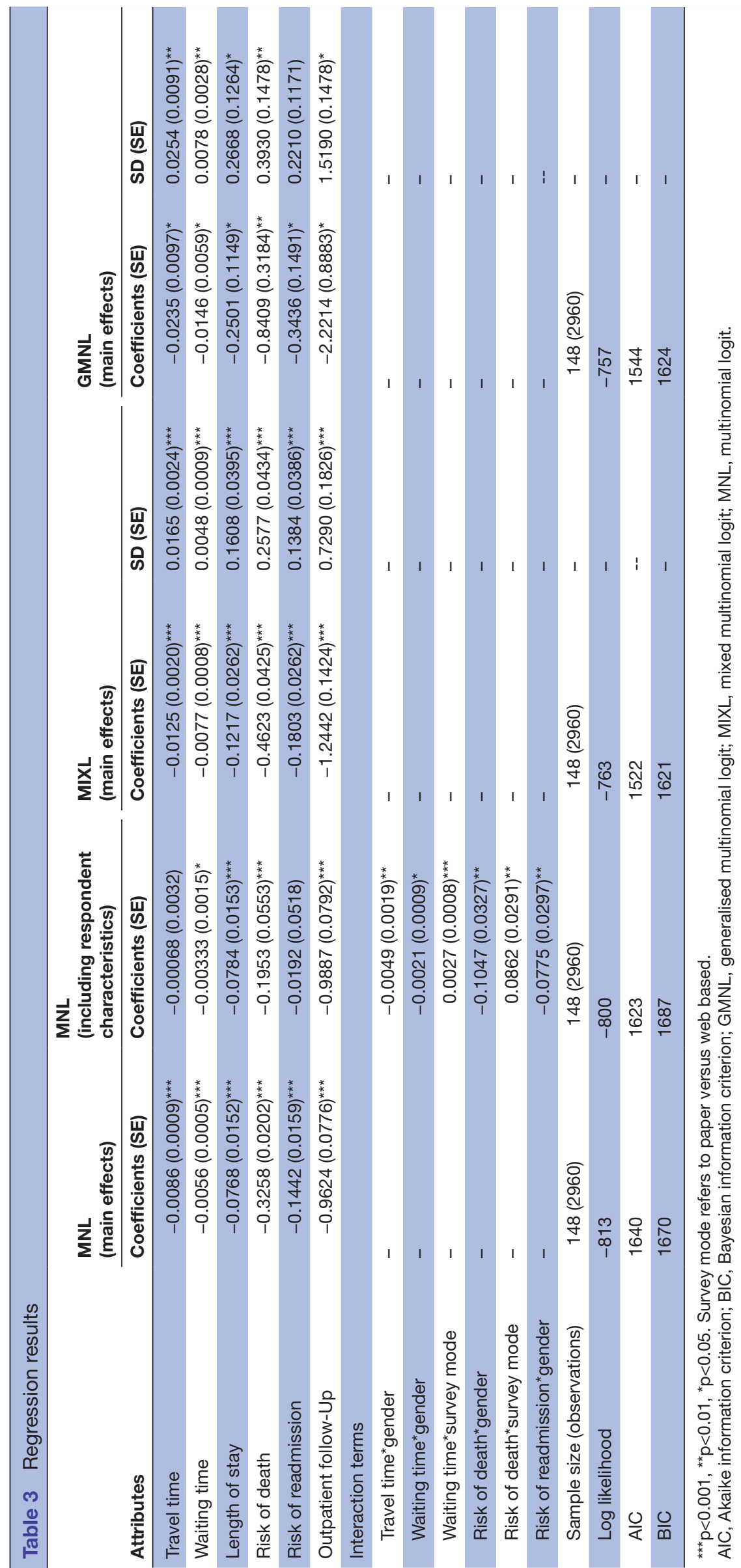


MRS in table 4. The MRS in model 1A indicated that participants were willing to travel 9 min more and willing to wait 14 min more for a 1 day reduction in length of stay in the hospital. The willingness to travel increased to 38 min and the willingness to wait increased to $58 \mathrm{~min}$ for one per cent reduction in risk of death in hospital. The willingness to travel was $112 \mathrm{~min}$ and willingness to wait was 172 min for having outpatient follow-up care after the emergency treatment at their local hospital. In model $1 \mathrm{~B}$, the coefficients of travel time and risk of readmission used to generate the MRS were not significant; therefore, the marginal willingness to travel across all attributes and marginal willingness to wait derived for the attribute risk of readmission were not significant. Nevertheless, the MRS estimates in all the models (except model 1B) were generally similar.

\section{DISCUSSION}

\section{Summary of the findings}

This examination of public preferences demonstrated the influence of attributes on the choice of hospitals in an emergency healthcare situation. In general, participants preferred shorter travel times, shorter waiting times, fewer number of days in hospital, low risk of death, low risk of readmission and local outpatient follow-up. Gender influenced the strength of the preference, with results suggesting that men have stronger preferences for shorter travel time, shorter waiting time, lower risk of death and lower risk of readmission compared with women. However, there was no evidence of influence of other characteristics such as age, recent experience of emergency care and current health state of the individual.

The results indicate that if centralisation of EMS increases travel and waiting times, but offered better care in terms of reduced risk of death, reduced length of stay, reduced risk of readmission and provisions for follow-up care in the local hospital, then participants would prefer the centralised service. Travelling $38 \mathrm{~min}$ longer by ambulance and waiting about an hour more for $1 \%$ reduction in risk of dying seems reasonable. The participants valued the opportunity for follow-up at their local hospital more than any other attributes examined in this DCE. Though travelling about 2 hours longer and waiting about 3 hours more may appear unrealistic value placed on local outpatient follow-up, these possibly reflect the feeling of emotional attachment and enormous pride of people towards their local NHS hospital. ${ }^{45}$ However, it was also found that the centralised hospital should also not be too far away to be acceptable (not needing more than 2 hours of additional travel time).

\section{Comparison with other studies}

While differences exist between studies in terms of healthcare context, design, attributes and levels used, the findings of this study are in line with other relevant DCE studies. Earlier studies attempting to quantify the strengths of individual preferences for unscheduled 
healthcare available during usual GP service hours have indicated that patients prefer shorter waiting times to get a decision on treatment and that services are provided closer to their homes. ${ }^{20}{ }^{46}$ Unlike our study, these studies reported age-related differences in strength of preferences: younger age groups ( $<45$ years) held strong preferences with respect to the way of making contact with the healthcare system. A study on Australian public's choice among alternatives of emergency care reported clear preferences for shorter waiting times and strong emphasis on the quality of emergency healthcare service. ${ }^{47}$ A significant preference heterogeneity was observed in this study and the strength of the preference changed according to the presenting context and situation such as the perceived severity of illness and who was being treated, but the influence of age and gender was not reported. Another DCE study which examined the factors influencing the choice of hospitals in London patients on waiting lists of range of non-emergency situations demonstrated that individuals prefer shorter travel time to hospital, shorter waiting time to receive the service, the follow-up care at their home hospital and a high valuation of hospital reputation. ${ }^{19}$ This study reported differences in preferences in patient related to gender and age suggesting that patients are more likely to prefer stay at their local hospitals as their age increases and men are more likely to choose to move to a non-local alternative hospital than women. Potential patients in Germany were willing to sacrifice longer travel distance and preferred location of care for a highly specialised surgical care provision with shorter waiting times, ${ }^{48}$ but the influence of respondent age and gender was not reported.

It is not surprising that non-emergency situations show similar results. A recent study assessing preferences for centralising specialist cancer services also found that patients, health professionals and the public all prefer shorter travel times, lower risk of death and complications, and better access to specialist centres. ${ }^{49}$ However, there was no evidence of differences because of gender, age or place of residence of the respondents. Risk of death and risk of complications were ranked highly whereas relatively lower importance was given to travel time.

\section{Implications of the study findings}

This study reveals preferences and the trade-offs individuals are willing to make across hospital attributes when choosing hospitals for emergency healthcare. The findings provide valuable insights for decision-makers in relation to the centralisation of emergency healthcare services. Contrary to the concerns about distance decay, ${ }^{11}{ }^{12}$ where the utilisation of healthcare services decreases with the increase in travel time to healthcare facilities, the findings suggest that while people may place a high value on their local hospital, in an emergency situation they may be willing to exchange increased journey time for better quality of care. This assumes that the ambulance response would be the same, and that other aspects of local services would not be affected, which may not be realistic but exploring this with the DCE would have added additional complexity that may make the tool difficult to complete. However, healthcare centralisation planners should also carefully consider how best to work with town and traffic planning services to help optimalise services or at the very least ensure that other system constraints do not remove any potential benefits of centralisation. The preferences are not influenced by age, health status or previous experience of EMS, suggesting that services do not necessarily have to be tailored according to age groups or health status, at least within the range of respondents studied. However, it was observed that there are gender differences in the strength of the preferences, which could possibly be related to the differences in knowledge, attitudes and previous healthcare experiences between men and women. ${ }^{50}$ While this finding may specifically reflect this cohort, it is recommended that future researchers and healthcare providers consider any communication about centralising services should be sensitive to gender differences while not allowing decisions about service provision to be driven by the preferences one particular gender especially without clearly understanding why these differences exist. Overall, the DCE results support policy recommendations to centralise emergency medical care in local hospitals into fewer specialised high performing units, ${ }^{34}$ as long as journey times are not excessively long and aftercare can be provided locally. However, our survey was framed to look at choices for emergency ambulance admissions and we caution that these findings may not reflect the preferences in 'blue-light' emergencies where the patient is not in a position to make the choice of which hospital to go to. Nevertheless, the preferences observed are for planning services and not for making decision about immediate care in an emergency.

\section{Strengths and limitations}

The findings of this study should be interpreted in light of some strengths and limitations. We attempted to study a wide cross section of a local unselected population to represent the preferences of potential users for a newly built centralised emergency hospital. However, due to the contact databases which were available for us to invite participants, it only represents specific population groups registered with the Healthwatch or Northumbria Healthcare NHS Foundation Trust, and sampling bias cannot be ruled out. While DCE offers several advantages over other preference elicitation methods used in healthcare, concerns have been expressed about their external validity. ${ }^{51}$ Despite a high proportion of complete responses in the DCE, a number of participants found the choice tasks difficult to complete which could mean the attributes were not appropriate to them and the choices were arbitrarily made. Furthermore, the attributes used in the DCE were taken from the literature solely and were not based on findings from qualitative research, ${ }^{52}$ nor was the choice of attributes and levels informed by any PPI. Consequently, other important attributes may have been left out. The attributes and their levels 
in the choice sets were framed to closely represent the emergency care in NHS England. However, the way the attributes were framed could possibly have influenced the choices made by respondents, ${ }^{53-55}$ and it is unclear whether choices would remain the same, if the attributes were framed in the other way, for example, would preferences have been different if 'risk of dying' was framed as 'chance of survival'? or if 'travel time' and 'waiting time' were used as a single attribute of 'call to treatment time'? But, merging the 'travel time' and 'waiting time' as a single attribute at the design stage would have reduced the explanatory power of the DCE. The presentation of attribute levels only in text formats could have created difficulties for some respondents in understanding the choice sets. Graphics and icons are often superior to text in communicating health information. ${ }^{56-58}$ However, it has been argued that within a DCE context, independent of educational level and literacy of respondents, words depicting attribute levels lead to more consistent answer patterns and more accurate attribute-level interpretation and estimates. ${ }^{54}$ One of the strengths of this survey lies in the fact that both survey modes-web based and postal (paper) -were used enabling us to increase the representation of a wider cross section of population. However, experimenting with the different approaches for survey administration was beyond the scope of this study, and use of different approaches might have introduced a response bias because of the systematic differences (eg, proportion of older people) between the respondents in each approach. The conventional practice of a DCE assumes that respondents choose among alternatives by rationally trading off across all attributes in their choice set. However, emerging evidence suggests that some respondents' tradeoff only a subset of attributes while choosing among alternatives. ${ }^{59-61}$ Failing to account for this phenomenon, widely referred to as attribute nonattendance, may lead to biassed preference estimates. ${ }^{62}$ A number of methods have been proposed in the literature to identify attribute non-attendance, which should be considered by future studies, such as asking respondents directly if they ignored any of the characteristics, use of econometric models such as latent class model to establish the probability of attribute non-attendance and use of eye-tracking technology. ${ }^{62-64}$ Finally, the study may not be generalised to other settings, because pre-existing local influences on experiences and views will vary, such as historical service performance, demographic mix and healthcare geography.

\section{CONCLUSION}

This study explored and quantified the strength of individual preferences relating to provision of EMS. The findings highlight that respondents prefer shorter travel time, shorter waiting time, fewer number of days in hospital, low risk of death, low risk of readmission and outpatient follow-up at their local hospital. However, people are willing to trade off increased travel time and waiting time for high-quality emergency medical care in a centralised hospital, in line with policy documents recommending centralisation. ${ }^{34}$ Decisions to centralise EMS should be justified on clinical grounds and cost savings, and need to be informed by preferences of potential service users.

Acknowledgements The authors acknowledge the support from Healthwatch Northumberland and Northumbria Health Care NHS Foundation Trust in conducting the survey. They thank the Health Foundation, London, for funding this study as a part of improvement science doctoral fellowship funded by the Health Foundation, London. They also thank the participants of the survey.

Contributors NB designed the DCE, implemented the survey, carried out the analyses and wrote the first draft of the manuscript. All authors conceived the study. All authors reviewed, commented, edited the manuscript and approved the final version of the manuscript.

Funding This work was funded by The Health Foundation, London.

Competing interests None declared.

Patient consent for publication Not required.

Ethics approval Ethics approval for the DCE survey was provided by Newcastle University Faculty of Medical Sciences Ethics Committee (approval code 00893/2015).

Provenance and peer review Not commissioned; externally peer reviewed. Data availability statement No data are available.

Open access This is an open access article distributed in accordance with the Creative Commons Attribution Non Commercial (CC BY-NC 4.0) license, which permits others to distribute, remix, adapt, build upon this work non-commercially, and license their derivative works on different terms, provided the original work is properly cited, appropriate credit is given, any changes made indicated, and the use is non-commercial. See: http://creativecommons.org/licenses/by-nc/4.0/.

\section{REFERENCES}

1 NHS England. The NHS belongs to the people: a call to action. London, 2013.

2 Fahy N, McKee M, Busse R, et al. How to meet the challenge of ageing populations. BMJ 2011;342.

3 NHS England. Five year forward view. London: NHS England, 2014.

4 NHS England. High quality care for all, now and for future generations: transforming urgent and emergency care services in England- urgent and emergency care review end of phase 1 report. London: NHS England, 2013.

5 Hunter RM, Davie C, Rudd A, et al. Impact on clinical and cost outcomes of a centralized approach to acute stroke care in London: a comparative effectiveness before and after model. PLoS One 2013;8:e70420.

6 Eichler K, Hess S, Chmiel C, et al. Sustained health-economic effects after reorganisation of a Swiss hospital emergency centre: a cost comparison study. Emerg Med J 2014;31:818-23.

7 Hunter RM, Fulop NJ, Boaden RJ, et al. The potential role of costutility analysis in the decision to implement major system change in acute stroke services in metropolitan areas in England. Health Res Policy Syst 2018;16.

8 Kelly C, Hulme C, Farragher T, et al. Are differences in travel time or distance to healthcare for adults in global North countries associated with an impact on health outcomes? A systematic review. BMJ Open 2016;6:e013059.

9 Nicholl J, West J, Goodacre S, et al. The relationship between distance to hospital and patient mortality in emergencies: an observational study. Emerg Med J 2007;24:665-8.

10 Roberts A, Blunt I, Bardsley M. Focus on: distance from home to emergency care. London: The Health Foundation and the Nuffield Trust, 2014

11 Raknes G, Hansen EH, Hunskaar S. Distance and utilisation of outof-hours services in a Norwegian urban/rural district: an ecological study. BMC Health Serv Res 2013;13:222.

12 Turnbull J, Martin D, Lattimer V, et al. Does distance matter? geographical variation in GP out-of-hours service use: an observational study. Br J Gen Pract 2008;58:471-7.

13 Beckert W, Christensen M, Collyer K. Choice of NHS-Funded hospital services in England. Econ J 2012;122:400-17. 
14 Ali S, Ronaldson S. Ordinal preference elicitation methods in health economics and health services research: using discrete choice experiments and ranking methods. Br Med Bull 2012;103:21-44.

15 Salampessy BH, Veldwijk J, Jantine Schuit A, et al. The predictive value of discrete choice experiments in public health: an exploratory application. Patient 2015;8:521-9.

16 Ryan M, Gerard K, Amaya-Amaya M. Using discrete choice experiments to value health and health care. Springer, 2008.

17 Ryan M, Mclntosh E, Dean T, et al. Trade-Offs between location and waiting times in the provision of health care: the case of elective surgery on the Isle of Wight. J Public Health 2000;22:202-10.

18 Shackley P, Slack R, Michaels J. Vascular patients' preferences for local treatment: an application of conjoint analysis. J Health Serv Res Policy 2001;6:151-7.

19 Burge P, Devlin N, Appleby J, et al. London Patient Choice Project Evaluation: A model of patients' choices of hospital from stated and revealed preference choice data: RAND Europe \& The King's Fund \&The City University, 2005.

20 Gerard K, Lattimer V. Preferences of patients for emergency services available during usual GP surgery hours: a discrete choice experiment. Fam Pract 2005;22:28-36.

21 Dixon A, Robertson R, Appleby J, et al. Patient choice: how patients choose and how providers respond. London: The King's Fund, 2010.

22 Sørup CM, Jacobsen P, Forberg JL. Evaluation of emergency department performance - a systematic review on recommended performance and quality-in-care measures. Scand J Trauma Resusc Emerg Med 2013;21:62.

23 The College of Emergency Medicine. Emergency department clinical quality indicators: -A CEM guide to implementation. London: The College of Emergency Medicine, 2011.

24 Cameron PA, Schull MJ, Cooke MW. A framework for measuring quality in the emergency department. Emergency Medicine Journal 2011;28:735-40.

25 Acute surveys co-ordination centre for the NHS patient survey programme. The key findings report for the 2008 emergency department survey: Picker Institute Europe, 2009.

26 Rose JM, Bliemer MCJ. Constructing efficient stated choice experimental designs. Transp Rev 2009;29:587-617.

27 Lancsar E, Louviere J. Conducting discrete choice experiments to inform healthcare decision making: a user's guide. Pharmacoeconomics 2008;26:661-77.

28 Rose JM, Bliemer MCJ, Hensher DA, et al. Designing efficient stated choice experiments in the presence of reference alternatives. Transportation Research Part B: Methodological 2008;42:395-406.

29 Lancsar E, Louviere J. Deleting 'irrational' responses from discrete choice experiments: a case of investigating or imposing preferences? Health Econ 2006;15:797-811.

30 Ozdemir S, Mohamed AF, Johnson FR, et al. Who pays attention in stated-choice surveys? Health Econ 2010;19:111-8.

31 ChoiceMetrics. Ngene 1.1.1 User Manual \& Reference Guide. Australia, 2012

32 de Bekker-Grob EW, Donkers B, Jonker MF, et al. Sample size requirements for Discrete-Choice experiments in healthcare: a practical guide. Patient 2015;8:373-84.

33 Orme B. Sample size issues for conjoint analysis studies. sawtooth software research paper series, 1998.

34 Orme B. Sample size issues for conjoint analysis studies. sawtooth software technical paper. Sequim 2010.

35 Lancaster KJ. A new approach to consumer theory. J Polit Econ 1966;74:132-57.

36 Miguel FS, Ryan M, Amaya-Amaya M. ?Irrational? stated preferences: a quantitative and qualitative investigation. Health Econ 2005;14:307-22

37 Ryan M, Watson V, Entwistle V. Rationalising the 'irrational': a think aloud study of discrete choice experiment responses. Health Econ 2009;18:321-36.

38 de Bekker-Grob EW, Ryan M, Gerard K. Discrete choice experiments in health economics: a review of the literature. Health Econ 2012;21:145-72.

39 Hensher DA, Greene WH. The mixed Logit model: the state of practice. Transportation 2003;30:133-76.

40 Hess S, Train K. Correlation and scale in mixed logit models. Journal of Choice Modelling 2017;23:1-8.

41 Fiebig DG, Keane MP, Louviere J, et al. The generalized multinomial Logit model: accounting for scale and coefficient heterogeneity. Marketing Science 2010;29:393-421.
42 Hauber AB, González JM, Groothuis-Oudshoorn CGM, et al. Statistical methods for the analysis of discrete choice experiments: a report of the ISPOR conjoint analysis good research practices Task force. Value in Health 2016;19:300-15.

43 R Core Team. R: a language and environment for statistical computing. Vienna, Austria: R Foundation for Statistical Computing, 2016.

44 Janssen B, Szende A. Population Norms for the EQ-5D. In: Szende A, Janssen B, Cabases J, eds. Self-Reported population health: an international perspective based on EQ-5D. Dordrecht. Springer Netherlands, 2014: 19-30.

45 Thomson M, Maclnnis DJ, Whan Park C. The Ties That Bind: Measuring the Strength of Consumers' Emotional Attachments to Brands. Journal of Consumer Psychology 2005;15:77-91.

46 Gerard Ket al. Reviewing emergency care systems 2: measuring patient preferences using a discrete choice experiment. Emergency Medicine Journal 2004;21:692-7.

47 Harris P, Whitty JA, Kendall E, et al. The Australian public's preferences for emergency care alternatives and the influence of the presenting context: a discrete choice experiment. BMJ Open 2015;5:e006820.

48 Schwappach DLB, Strasmann TJ. Does location matter? A study of the public?s preferences for surgical care provision. J Eval Clin Pract 2007;13:259-64.

49 Vallejo-Torres L, Melnychuk M, Vindrola-Padros C, et al. Discretechoice experiment to analyse preferences for centralizing specialist cancer surgery services. Br J Surg 2018;105:587-96.

50 Wessels H, de Graeff A, Wynia K, et al. Gender-Related needs and preferences in cancer care indicate the need for an individualized approach to cancer patients. Oncologist 2010;15:648-55.

51 Quaife M, Terris-Prestholt F, Di Tanna GL, et al. How well do discrete choice experiments predict health choices? A systematic review and meta-analysis of external validity. Eur $J$ Health Econ 2018:19:1053-66.

52 Vass C, Rigby D, Payne K. The role of qualitative research methods in discrete choice experiments. Med Decis Making 2017;37:298-313.

53 Kragt ME, Bennett JW. Attribute framing in choice experiments: how do attribute level descriptions affect value estimates? Environmental and Resource Economics 2012;51:43-59.

54 Veldwijk J, Lambooij MS, van Til JA, et al. Words or graphics to present a discrete choice experiment: does it matter? Patient Educ Couns 2015:98:1376-84.

55 Veldwijk J, Essers BAB, Lambooij MS, et al. Survival or mortality: does risk attribute framing influence decision-making behavior in a discrete choice experiment? Value in Health 2016;19:202-9.

56 Tait AR, Voepel-Lewis T, Zikmund-Fisher BJ, et al. Presenting research risks and benefits to parents: does format matter? Anesth Analg 2010;111:718-23.

57 Tait AR, Voepel-Lewis T, Zikmund-Fisher BJ, et al. The effect of format on parents' understanding of the risks and benefits of clinical research: a comparison between text, tables, and graphics. J Health Commun 2010;15:487-501.

58 McCaffery KJ, Dixon A, Hayen A, et al. The influence of graphic display format on the interpretations of quantitative risk information among adults with lower education and literacy. Med Decis Making 2012;32:532-44.

59 Hensher DA, Rose J, Greene WH. The implications on willingness to pay of respondents ignoring specific attributes. Transportation 2005;32:203-22.

60 Carlsson F, Kataria M, Lampi E. Dealing with Ignored Attributes in Choice Experiments on Valuation of Sweden's Environmental Quality Objectives. Environmental and Resource Economics 2010;47:65-89.

61 Colombo S, Christie M, Hanley N. What are the consequences of ignoring attributes in choice experiments? implications for ecosystem service valuation. Ecological Economics 2013:96:25-35.

62 Hensher DA, Greene WH. Non-attendance and dual processing of common-metric attributes in choice analysis: a latent class specification. Empir Econ 2010;39:413-26.

63 Hole AR, Kolstad JR, Gyrd-Hansen D. Inferred vs. stated attribute non-attendance in choice experiments: A study of doctors' prescription behaviour. J Econ Behav Organ 2013;96:21-31.

64 Spinks J, Mortimer D. Lost in the crowd? using eye-tracking to investigate the effect of complexity on attribute non-attendance in discrete choice experiments. BMC Med Inform Decis Mak 2016;16:14 